\title{
Selective Determination of Lead in Complicated Environmental Samples by Displacement Dispersive Liquid-liquid Microextraction and Graphite Furnace Atomic Absorption Spectrometry
}

\author{
Pei Liang*, Caiyan Kang, and Lijuan Wen \\ Key Laboratory of Pesticide \& Chemical Biology of Ministry of Education, College of Chemistry, \\ Central China Normal University, Wuhan 430079, P.R. China
}

\section{INTRODUCTION}

Lead $(\mathrm{Pb})$ is one of the most toxic elements, with an accumulative effect and environmental toxicity, and is classified as a Group B2 (probable) human carcinogen by the United States Environmental Protection Agency (USEPA) (1). Pb can affect almost all organs and systems in the human body, resulting in blood enzyme changes, hyperactivity, and neurological disorders $(2,3)$. However, its unique properties make it useful as an industrial material in diverse fields, but released into the environment in considerable amounts finally leads to bioaccumulation in the living organisms through diverse pathways. Consequently, the development of reliable analytical methods for the determination of $\mathrm{Pb}$ is of great importance for the effective monitoring of pollution levels in the environment and the critical evaluation of possible risks to human health.

The direct determination of $\mathrm{Pb}$ in environmental samples is often difficult due to matrix effects and the low concentration of $\mathrm{Pb}$. In order to achieve accurate and reliable analytical results, an initial sample pretreatment procedure for analyte preconcentration and matrix separation is often required. Several methods have been reported for the separation and preconcentration of $\mathrm{Pb}$, such as co-precipitation (4), liquid-liquid extraction (LLE) (5), solid-phase extraction

\section{ABSTRACT}

A novel method was developed for the selective determination of lead $(\mathrm{Pb})$ in environmental samples by displacement dispersive liquid-liquid microextraction (D-DLLME) combined with graphite furnace atomic absorption spectrometry (GFAAS). This D-DLLME method involves two steps of dispersive liquid-liquid microextraction (DLLME). Firstly, $\mathrm{Zn}^{2+}$ reacted with diethyldithiocarbamate (DDTC) to form the Zn-DDTC complex and was then extracted with the DLLME procedure. Then the sediment phase was dispersed into the sample solution containing $\mathrm{Pb}^{2+}$ with a dispersive solvent; then another DLLME procedure was carried out. Since the stability of Pb-DDTC is higher than that of $\mathrm{Zn}-\mathrm{DDTC}, \mathrm{Pb}^{2+}$ can displace $\mathrm{Zn}^{2+}$ from the preextracted Zn-DDTC complex and be preconcentrated into the sediment phase. The interference from co-existing metal ions with a lower DDTC complex stability was largely eliminated as they cannot displace $\mathrm{Zn}^{2+}$ from the Zn-DDTC complex. Under the optimal conditions, the limit of detection was $35 \mathrm{ng} \mathrm{L}^{-1}(3 \sigma)$ for lead, and an enhancement factor of 91 was achieved with a sample volume of $5.0 \mathrm{~mL}$. The proposed method has been successfully applied to the determination of trace lead in environmental samples with satisfactory results.
(SPE) $(6,7)$, cloud point extraction (CPE) $(8,9)$, and liquid-phase microextraction (LPME) $(10,11)$. However, disadvantages such as time-consuming, unsatisfactory enrichment factors, and requiring large amounts of organic solvents limit their application.

Dispersive liquid-liquid microextraction (DLLME) is a novel liquidliquid extraction protocol based on ternary component solvent systems $(12,13)$. The method has the advantages of simplicity of operation, speed, low cost, high recovery, and enrichment factors, and has proven to be a suitable preconcentration procedure for various metal ions $(14,15)$. The DLLME preconcentration of metal ions often requires the formation of a hydrophobic metal chelate and also suffers undesirable interference from co-existing metal ions, especially in complicated matrices, owing to the competition for the complexing reagent. In fact, all metal chelate-based preconcentration systems have encountered such problems (16). To overcome this problem, a displacement-sorption preconcentration protocol based on the stability difference of the metal chelate was developed for highly selective quantification of metal ions in complicated matrices (17). The metal of interest (M1) with a higher complex stability can take the place of another metal (M2) with lower complex stability from its complex, whereas the reverse reaction cannot occur. Through the displacement reaction, interferences from co-existing metal ions were greatly eliminated 
and efficient analyte preconcentration can be achieved simultaneously. This displacement-sorption preconcentration method has been successfully applied for the determination of mercury $(\mathrm{Hg})$ in environmental and biological samples (18), methylmercury in fish samples $(19,20)$, palladium (Pd) in road dusts (21), and silver (Ag) in water samples (22). This same principle was also employed by using a displacement cloud point extraction method for the selective determination of silver (Ag) and copper (Cu) $(23,24)$.

The purpose of this work is to apply a recently developed displacement dispersive liquid-liquid microextraction (D-DLLME) method (25) for the selective determination of $\mathrm{Pb}$ in complicated environmental samples by graphite furnace atomic absorption spectrometry (GFAAS). The extraction steps of D-DLLME are illustrated in Figure 1. In this work, diethyldithiocarbamate (DDTC) was selected as the chelating reagent, and $\mathrm{Zn}^{2+}$ was employed as the pre-extraction metal ion for best selectivity of the displacement reaction. The optimal conditions of the extraction solvent and the dispersive solvent for the DLLME preconcentration of $\mathrm{Zn}$ and $\mathrm{Pb}$ have been studied in previous works $(26,27)$ and are used directly in this work. For this D-DLLME method, the extraction efficiency depends on the displacement reaction between $\mathrm{Pb}$ and $\mathrm{Zn}-\mathrm{DDTC}$. Systematic optimization of the conditions affecting the displacement reaction was therefore carried out to obtain optimal performance of the D-DLLME procedure.

\section{EXPERIMENTAL}

\section{Instrumentation}

A TAS-990 atomic absorption spectrophotometer (Beijing Purkinje General Instrument Co. Ltd., Beijing, P.R. China), equipped with a deuterium background corrector and GF990 graphite furnace atomizer system, was used. A Pb hollow cathode lamp was used as the radiation source at $283.3 \mathrm{~nm}$. The optimum operating parameters for GFAAS are given in Table I. All measurements were carried out in the integrated absorbance (peak area) mode. The $\mathrm{pH}$ values were measured with a Mettler Toledo 320-S pH meter (Mettler Toledo Instruments Co. Ltd. , Shanghai, P.R. China). A Model 0412-1 centrifuge (Shanghai Surgical Instrument Factory, Shanghai, P.R. China) was used to accelerate phase separation. A model MK-III microwave digestion system (Shinco Institute of Microwave Digestion Technology, Shanghai, P.R. China) was used to dissolve the solid samples.

\section{Standard Solution and Reagents}

Stock standard solutions (1000 $\mathrm{mg} \mathrm{L}^{-1}$ ) of $\mathrm{Pb}$ and $\mathrm{Zn}$ were obtained from the National Institute of Stan-

TABLE I

GFAAS Operating Parameters

\begin{tabular}{ll}
\hline Parameters & \\
\hline Lamp current & $2.0 \mathrm{~mA}$ \\
Wavelength & $283.3 \mathrm{~nm}$ \\
Slit/nm & $0.4 \mathrm{~nm}$ \\
Ar flow rate & $300 \mathrm{~mL} \mathrm{m^{-1 }}$ (stopped during atomizing) \\
Sample volume & $20 \mu \mathrm{L}$ \\
\hline Temperature Program & \\
\hline Drying & $110^{\circ} \mathrm{C}(\operatorname{Ramp~} 15 \mathrm{~s}$, Hold $10 \mathrm{~s})$ \\
Ashing & $500^{\circ} \mathrm{C}(\operatorname{Ramp} 15 \mathrm{~s}$, Hold $10 \mathrm{~s})$ \\
Atomizing & $1900^{\circ} \mathrm{C}(\operatorname{Ramp} 0 \mathrm{~s}$, Hold $3 \mathrm{~s})$ \\
Cleaning & $2200{ }^{\circ} \mathrm{C}(\operatorname{Ramp} 1 \mathrm{~s}$, Hold $3 \mathrm{~s})$ \\
\hline
\end{tabular}

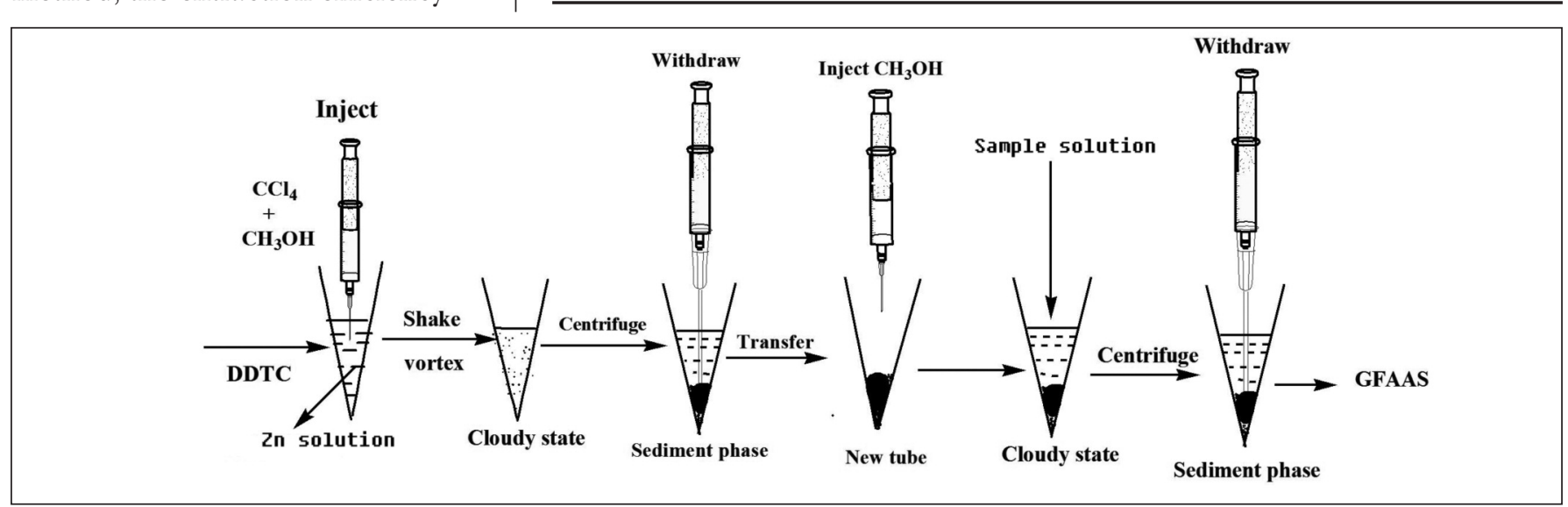

Fig. 1. Schematic of D-DLLME procedure. 
dards (Beijing, P.R. China). Working standard solutions were obtained by appropriate dilution of the stock standard solution. The solution of DDTC was prepared by dissolving appropriate amounts of sodium diethyldithiocarbamate (AR, Shanghai Chemistry Reagent Company, Shanghai, P.R. China) in doubly distilled water. All other reagents used were of the highest available purity and of at least analytical reagent grade. Doubly distilled water was used throughout. Pipettes and vessels used in the experiments were kept in 10\% nitric acid for at least 24 hours and subsequently washed four times with doubly distilled water.

\section{Displacement Dispersive Liquid-liquid Microextraction Procedure}

Aliquots of 5.0-mL sample solution containing $10 \mu \mathrm{g} \mathrm{L}^{-1} \mathrm{Zn}^{2+}$, $0.02 \mathrm{~g} \mathrm{~L}^{-1}$ DDTC, and $0.02 \mathrm{~mol} \mathrm{~L}^{-1}$ $\mathrm{HNO}_{3}$ were placed into $10-\mathrm{mL}$ screw cap glass test tubes with a conical bottom. An amount of 0.5 $\mathrm{mL}$ of methanol (dispersive solvent) containing $60 \mu \mathrm{L}$ of carbon tetrachloride $\left(\mathrm{CCl}_{4}\right.$, extraction solvent) was injected rapidly into the sample solution by using a $1.00-\mathrm{mL}$ microsyringe. After a cloudy solution was formed in the test tube, the $\mathrm{Zn}$-DDTC complex was extracted into the fine droplets of $\mathrm{CCl}_{4}$. Then, the solution was centrifuged at $3500 \mathrm{rpm}$ for 5 minutes, and the dispersed fine droplets of $\mathrm{CCl}_{4}$ were deposited at the bottom of the conical test tube (about $35 \mu \mathrm{L}$ ). After removing the aqueous phase, the sediment phase was dissolved with $0.2 \mathrm{~mL}$ methanol and injected into a 5.0-mL sample solution containing $\mathrm{Pb}$ and $0.02 \mathrm{~mol} \mathrm{~L}{ }^{-1} \mathrm{HNO}_{3}$, then another cloudy solution was formed and incubated for $5 \mathrm{~min}$ utes. In this step, $\mathrm{Pb}$ can replace $\mathrm{Zn}$ from the pre-extracted Zn-DDTC complex and enter into the sediment phase. After centrifuging, $20 \mu \mathrm{L}$ of the sediment phase at the bottom of conical test tube (about $25 \mu \mathrm{L}$ ) was removed using a $50-\mu \mathrm{L}$ microsyringe and injected into the GFAAS for the determination of $\mathrm{Pb}$.

Calibration was performed against aqueous standards submitted to the same D-DLLME procedure. A blank submitted to the same procedure described above was measured parallel to the sample and calibration solutions.

\section{Sample Preparation}

Two environmental certified reference materials (CRMs) GBW07104 Ore and GBW08401 Coal Fly Ash (obtained from the Perambulation Institute of Physical Geography and Geochemistry of the Geological and Mineral Ministry, Langfang, P.R. China) were used to check the accuracy of the developed method. All samples were dried in an oven at $60^{\circ} \mathrm{C}$. A portion (0.1-0.2 g) of the dried samples was accurately weighed into a PTFE vessel, treated with $6 \mathrm{~mL}$ of $\mathrm{HF}, 5 \mathrm{~mL}$ of concentrated $\mathrm{HNO}_{3}$, and $3 \mathrm{~mL}$ of concentrated $\mathrm{H}_{2} \mathrm{SO}_{4}$. Then the vessel was submitted to a power program in the microwave oven. The heating steps with a duration of 5 minutes each and a power of 250,400, and 650 W were applied. The program was repeated twice to obtain a clear solution. The solution was heated to near dryness and the residue dissolved in $0.1 \mathrm{~mol} \mathrm{~L}^{-1} \mathrm{HNO}_{3}$. The final volume was made up to $100 \mathrm{~mL}$ with doubly distilled water.

\section{RESULTS AND DISCUSSION}

\section{Effect of Pre-extraction Solution and Sample Solution Acidity}

The acidity of the pre-extraction solution (acidity of the $\mathrm{Zn}$ solution) influences the formation of the Zn-DDTC complex and its extraction and the subsequent extraction of $\mathrm{Pb}$. The acidity of the solution was adjusted with dilute $\mathrm{HNO}_{3}$, its effect on the absorbance signal of $\mathrm{Pb}$ was investigated in the $\mathrm{HNO}_{3}$ concentration range of $0-0.2$ mol L ${ }^{-1}$, and the results are shown in Figure 2. The highest $\mathrm{Pb}$ signal was obtained with a $\mathrm{HNO}_{3}$ concentration of $0.02 \mathrm{~mol} \mathrm{~L}^{-1}$. Therefore, the pre-extraction process was performed in a $0.02 \mathrm{~mol} \mathrm{~L}^{-1} \mathrm{HNO}_{3}$ solution.

The sample solution acidity (acidity of the $\mathrm{Pb}$ solution) influences the stability of the Pb-DDTC

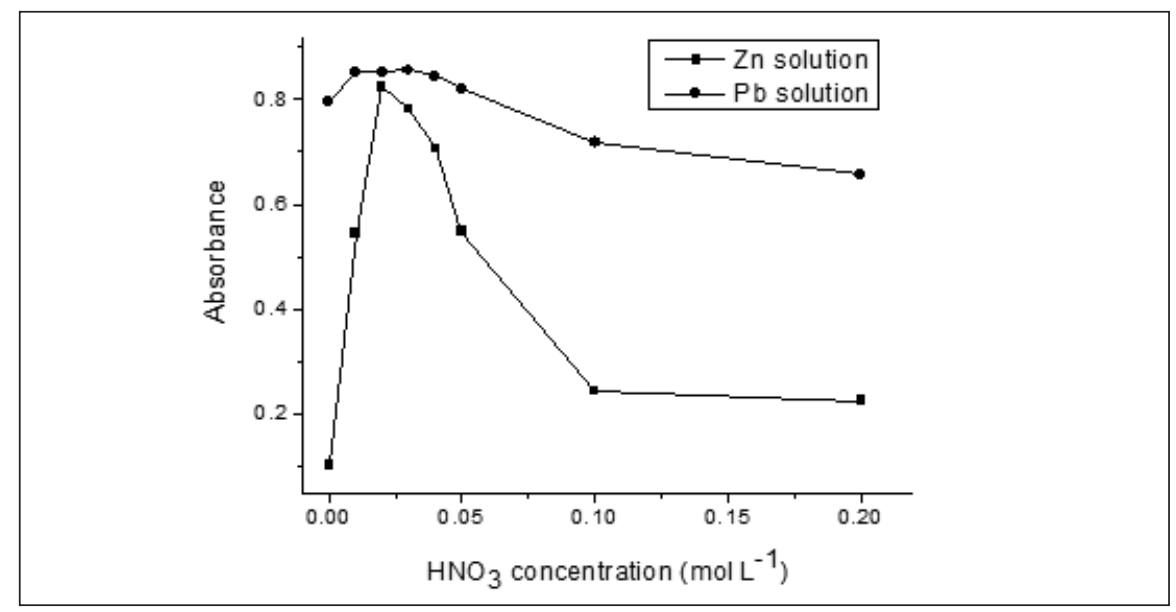

Fig. 2. Effect of acidity of the pre-extraction solution and the sample solution on the D-DLLME of Pb. Experimental conditions: $\mathrm{Zn} 10 \mu \mathrm{g} \mathrm{L}{ }^{-1}$; Pb $1.0 \mu \mathrm{g} \mathrm{L}^{-1}$; sample volume $5.0 \mathrm{~mL}$; dispersive solvent (methanol) volume, pre-extraction $0.5 \mathrm{~mL}$, displacement extraction $0.2 \mathrm{~mL}$; extraction solvent $\left(\mathrm{CCl}_{4}\right)$ volume $60 \mu \mathrm{L}$; DDTC concentration $0.02 \mathrm{~g} \mathrm{~L}^{-1}$. 
complex and the displacement reaction. The effect of the sample solution acidity on the absorbance signal of $\mathrm{Pb}$ was investigated in the range of $0-0.2 \mathrm{~mol} \mathrm{~L}^{-1} \mathrm{HNO}_{3}$, and the result is also presented in Figure 2 . It can be seen that the highest signal of $\mathrm{Pb}$ was obtained at the $\mathrm{HNO}_{3}$ concentration range of 0.01-0.05 $\mathrm{mol} \mathrm{L}^{-1}$. Thus, the sample solution acidity was adjusted to $0.02 \mathrm{~mol} \mathrm{~L}^{-1} \mathrm{HNO}_{3}$ for the second extraction process.

\section{Effect of DDTC Concentration}

The concentration of DDTC has a direct effect on the formation of the Zn-DDTC complex and its preextraction as well as the displacement reaction between $\mathrm{Pb}$ and Zn-DDTC. The effect of DDTC concentration on the absorbance signal of $\mathrm{Pb}$ was investigated in the range of $0-0.1 \mathrm{~g} \mathrm{~L}^{-1}$, and the result is shown in Figure 3. As can be seen, the absorbance signal of $\mathrm{Pb}$ increased with an increase in DDTC concentration up to $0.02 \mathrm{~g} \mathrm{~L}^{-1}$, and then remained constant. Thereby, a DDTC concentration of $0.02 \mathrm{~g} \mathrm{~L}^{-1}$ was selected for further studies.

\section{Effect of $\mathrm{Zn}$ Concentration}

The $\mathrm{Zn}^{2+}$ concentration influences the amount of pre-extracted $\mathrm{Zn}$ DDTC and the subsequent displacement reaction. Studies on the effect of the $\mathrm{Zn}^{2+}$ concentration showed that the absorbance signal of $\mathrm{Pb}$ increased with an increase in $\mathrm{Zn}^{2+}$ concentration up to $10 \mu \mathrm{g} \mathrm{L}^{-1}$, and then remained constant with a further increase in $\mathrm{Zn}^{2+}$ concentration. For further experiments, a $\mathrm{Zn}^{2+}$ concentration of $10 \mu \mathrm{g} \mathrm{L}^{-1}$ was used.

\section{Effect of Volume of Extraction Solvent}

In the first extraction process, $\mathrm{CCl}_{4}$ was used as the extraction solvent and is based on a previous study (26). The effect of the volume of $\mathrm{CCl}_{4}$ on the absorbance signal of $\mathrm{Pb}$ was studied ranging from $40 \mu \mathrm{L}$ to $80 \mu \mathrm{L}$. It was found that the absorbance signal of $\mathrm{Pb}$ decreased with an increase in the volume of $\mathrm{CCl}_{4}$, and the enhancement factor also decreased from 112 to 54 , because the volume of the sediment phase increased from 20 to $60 \mu \mathrm{L}$. In order to ensure the sediment phase enough for the second extraction process, $60 \mu \mathrm{L} \mathrm{CCl}_{4}$

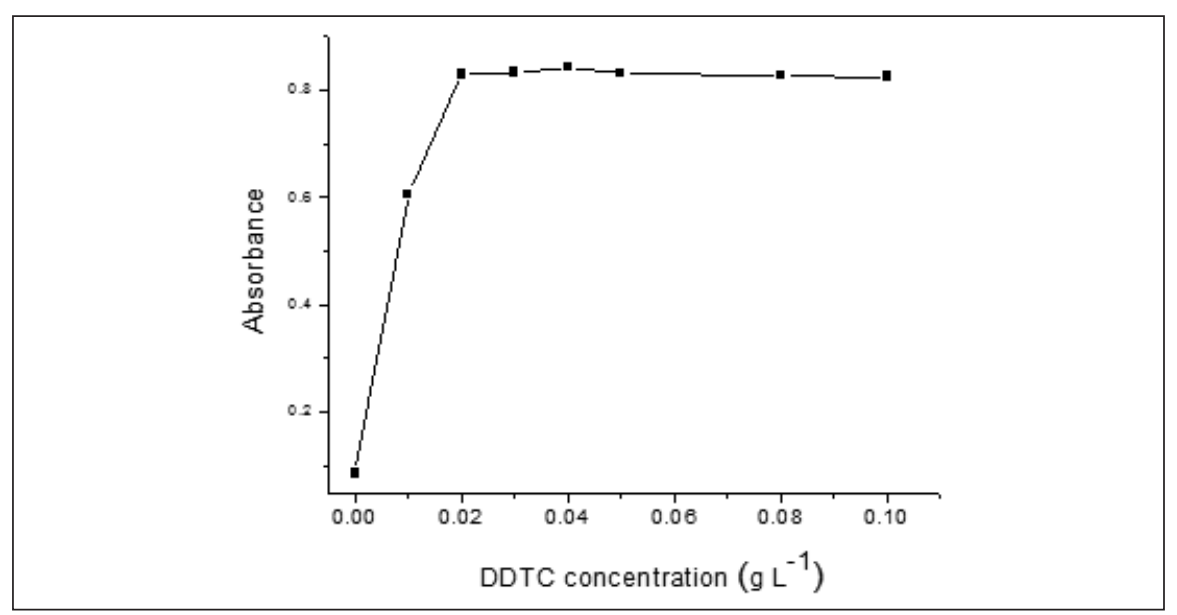

Fig. 3. Effect of DDTC concentration on the D-DLLME of Pb.

Experimental conditions: $\mathrm{Zn} 10 \mu \mathrm{g} \mathrm{L}^{-1}$; Pb $1.0 \mu \mathrm{g} \mathrm{L}^{-1}$; sample volume $5.0 \mathrm{~mL} ; \mathrm{HNO}_{3}$ concentration $0.02 \mathrm{~mol} \mathrm{~L}^{-1}$ in the pre-extracted solution and the sample solution; dispersive solvent (methanol) volume, the pre-extraction $0.5 \mathrm{~mL}$, the displacement extraction $0.2 \mathrm{~mL}$; extraction solvent $\left(\mathrm{CCl}_{4}\right)$ volume $60 \mu \mathrm{L}$.

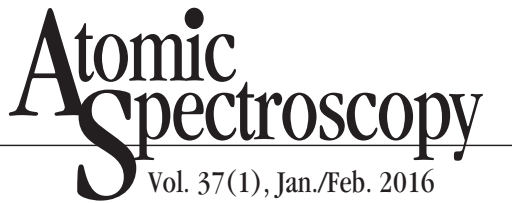

was used as the extraction solvent for this work.

\section{Effect of Volume of Dispersive Solvent}

In the second extraction process, the sediment phase of the first extraction process was dispersed into the sample solution as the extraction solvent using methanol as the dispersive solvent. The effect of the volume of methanol on the absorbance signal of $\mathrm{Pb}$ was studied. It was found that the absorbance signal of $\mathrm{Pb}$ increased with a methanol volume up to $0.20 \mathrm{~mL}$, and then decreased remarkably as the volume of methanol increased. Therefore, $0.20 \mathrm{~mL}$ methanol was used as the dispersive solvent in the second extraction process.

\section{Effect of Extraction Time}

In the second DLLME procedure, the extraction time may affect the displacement reaction between $\mathrm{Pb}$ and $\mathrm{Zn}$-DDTC and the extraction efficiency. The effect of extraction time was examined in the range of 30 seconds to 10 minutes using the constant experimental conditions. The obtained results showed that the absorbance signal of $\mathrm{Pb}$ remains constant after the extraction time exceeded 5 minutes. Thus, an extraction time of 5 minutes was employed in the second DLLME procedure.

\section{Pyrolysis and Atomization Curves}

Pyrolysis and atomization curves were established using $1.0 \mu \mathrm{g} \mathrm{L}^{-1}$ of $\mathrm{Pb}$ solution submitted to the D-DLLME procedure, and the results are shown in Figure 4. From these curves, a pyrolysis temperature of $500{ }^{\circ} \mathrm{C}$ and an atomization temperature of $1900{ }^{\circ} \mathrm{C}$ were selected for this work.

\section{Interference Evaluation}

Due to the introduction of the displacement reaction, an improve- 
ment of the tolerable limits for the interference species in the D-DLLME method was expected. The effects of several potentially interfering species were carefully studied and the results are listed in Table II as well as the results obtained with the conventional DLLME method (27). The results show that the D-DLLME method has large improvements in the tolerable limit of coexisting heavy metal ions. The presence of large amounts of alkaline and alkaline earth metal ions have no interference effect on the D-DLLME extraction of $\mathrm{Pb}$ because they cannot complex with DDTC. These results clearly demonstrated the high selectivity of the developed D-DLLME method for the determination of trace $\mathrm{Pb}$.

\section{Characteristics of the Method}

Under the optimal experimental conditions, the calibration curve was linear over the range of 0.1-10 $\mu \mathrm{g} \mathrm{L^{-1 }}$ with a correlation coefficient (r) of 0.9993 . The limit of detection
(LOD), calculated as three times the standard deviation of 11 replicate measurements of the blank solution, was $35 \mathrm{ng} \mathrm{L}^{-1}$. The precision of this method was determined by analyzing a standard solution at $\mathbf{1 . 0}$ $\mu \mathrm{g} \mathrm{L} \mathrm{L}^{-1}$ of $\mathrm{Pb}$ in sequence for seven times, and the relative standard deviation (RSD) was 3.1\%. The enhancement factor, calculated as the ratio of the analytical signal of $\mathrm{Pb}$ obtained after and before extraction, was 91 for a 5.0-mL sample solution.

\section{Analysis of Real Samples}

In order to establish the validity of the proposed method, $\mathrm{Pb}$ was determined in two environmental certified reference materials GBW07104 Ore and GBW08401 Coal Fly Ash. The analytical results listed in Table III show that the determined values were in good agreement with the certified values despite the complicated matrices of these samples.

The proposed method has also been applied to the determination of $\mathrm{Pb}$ in river water, lake water, and tap water samples. The river water sample was collected from the Yangtze River (Wuhan, P.R. China), the lake water sample was collected from East Lake (Wuhan, P.R. China), and the tap water sample was freshly collected in our laboratory after allowing the water to flow for 5 minutes. All water samples were filtered through a $0.45-\mu \mathrm{m}$ membrane filter and analyzed as soon as possible after sampling. In addition, the recovery experiments of different amounts of $\mathrm{Pb}$ were carried out. The results listed in Table IV show that the recoveries in the range of 97-104\% are reasonably well for trace analysis.

\section{CONCLUSION}

Under the optimal conditions, a limit of detection of $35 \mathrm{ng} \mathrm{L}^{-1}$ and an enhancement factor of 91 were achieved for lead by the developed D-DLLME method with a sample volume of $5.0 \mathrm{~mL}$. Compared with the conventional DLLME method,

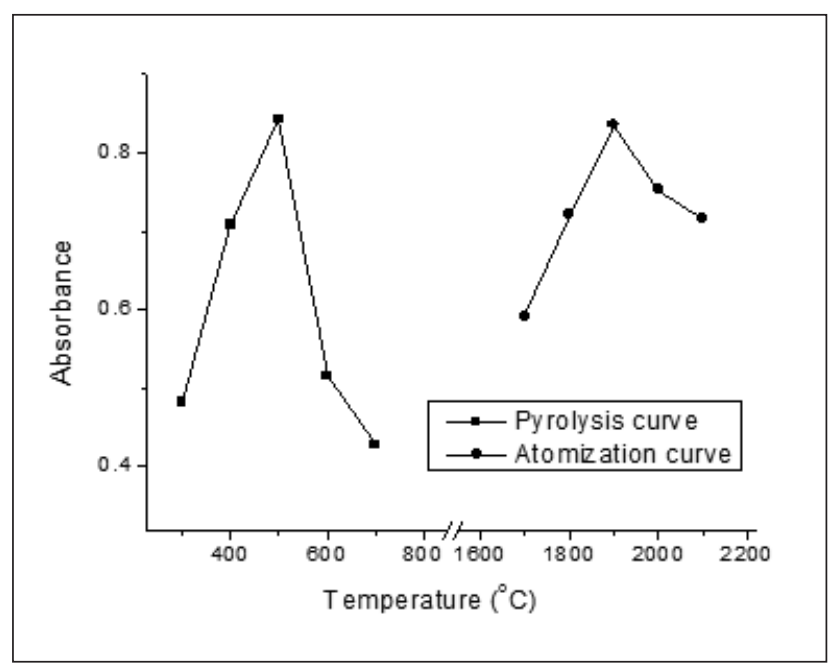

Fig. 4. Pyrolysis curve and atomization curve for $\mathrm{Pb}$. Experimental conditions: $\mathrm{Zn} 10 \mu \mathrm{g} \mathrm{L}^{-1}$; Pb $1.0 \mu \mathrm{g} \mathrm{L}^{-1}$; sample volume $5.0 \mathrm{~mL} ; \mathrm{HNO}_{3}$ concentration $0.02 \mathrm{~mol} \mathrm{~L}^{-1}$ in the pre-extracted solution and the sample solution; dispersive solvent (methanol) volume, pre-extraction $0.5 \mathrm{~mL}$, displacement extraction $0.2 \mathrm{~mL}$; extraction solvent $\left(\mathrm{CCl}_{4}\right)$ volume $60 \mu L ;$ DDTC concentration $0.02 \mathrm{~g} \mathrm{~L}^{-1}$.
TABLE II

Tolerance Limits of Coexisting Ions

\begin{tabular}{lcc}
\hline $\begin{array}{c}\text { Coexisting } \\
\text { Ions }\end{array}$ & \multicolumn{2}{c}{$\begin{array}{c}\text { Tolerance Limits } \\
(\text { coexisting ion/ Pb ratio }\end{array}$} \\
\hline & $\begin{array}{c}\text { Displacement } \\
\text { DLLME }\end{array}$ & $\begin{array}{c}\text { Conventional } \\
\text { DLLME }(27)\end{array}$ \\
\hline $\mathrm{K}^{+}, \mathrm{Na}^{+}$ & 600,000 & 500,000 \\
$\mathrm{Ca}^{2+}, \mathrm{Mg}^{2+}$ & 600,000 & 100,000 \\
$\mathrm{Al}^{3+}, \mathrm{Cr}^{3+}$ & 50,000 & 500 \\
$\mathrm{Cd}^{2+}, \mathrm{Mn}^{2+}, \mathrm{Co}^{2+}$ & 50,000 & 1000 \\
$\mathrm{Cu}^{2+}, \mathrm{Ni}^{2+}$ & 5,000 & 1000 \\
$\mathrm{Fe}^{3+}$ & 1,000 & 100 \\
$\mathrm{SO}_{4}{ }^{2-}, \mathrm{NO}_{3}^{-}, \mathrm{Cl}^{-}$ & $1,000,000$ & 500,000 \\
\hline
\end{tabular}

${ }^{\mathrm{a}} \mathrm{Pb}$ concentration, $1.0 \mu \mathrm{g} \mathrm{\textrm {L } ^ { - 1 }}$.

Table III

Analytical Results for $\mathbf{P b}$ in Certified Reference Materials (ng $\mathbf{g}^{-1}$, mean $\pm \sigma, \mathbf{n}=5$ )

\begin{tabular}{lcc}
\hline Samples & Found & Certified value \\
\hline GBW07104 Ore & $12.5 \pm 2.4$ & $11.3 \pm 2.8$ \\
GBW08401 Coal Fly Ash & $31.6 \pm 3.2$ & $33.8 \pm 2.2$ \\
\hline
\end{tabular}


TABLE IV

Determination of $\mathrm{Pb}\left(\mu \mathrm{g} \mathrm{L}^{-1}\right)$ in Water Samples

\begin{tabular}{lcrc}
\hline Samples & Added & \multicolumn{1}{c}{ Found $^{\mathrm{a}}$} & Recovery (\%) \\
\hline River Water & 0 & $3.27 \pm 0.12$ & - \\
& 5 & $8.12 \pm 0.54$ & 97 \\
& 10 & $13.18 \pm 0.88$ & 99 \\
Lake Water & 0 & $5.62 \pm 0.23$ & - \\
& 5 & $10.83 \pm 0.68$ & 104 \\
& 10 & $15.45 \pm 1.02$ & 98 \\
Tap Water & 0 & $1.09 \pm 0.07$ & \\
& 0.5 & $1.60 \pm 0.14$ & 102 \\
& 1.0 & $2.09 \pm 0.18$ & 100 \\
\hline
\end{tabular}

${ }^{\mathrm{a}}$ mean \pm S.D., $\mathrm{n}=5$.

the proposed D-DLLME method effectively minimizes the interference from co-existing heavy metal ions without the need of any masking reagents. These results demonstrate that the developed method is simple, rapid, selective, and sensitive, and has a promising future in routine applications for the determination of trace amounts of $\mathrm{Pb}$ in relatively complicated matrices.

\section{ACKNOWLEDGMENT}

This study was financially supported by self-determined research funds of CCNU from the colleges' basic research and operation of MOE (CCNU15A05020).

Received May 6, 2015.

\section{REFERENCES}

1. United States Environmental Protection Agency (USEPA), Lead and Copper Rule (LCR) 56 FR (1991).

2. H.R. Pohl, H.G. Abadin and J.F. Risher, Neurodegenerative Diseases and Metal Ions: Metal Ions in Life Sciences, Vol. 1, Wiley, Chichester, UK, pp. 397-408 (2006).

3. G. Nordberg, Handbook on the Toxicology of Metals, Academic Press, New York, NY, USA (2007).
4. S. Saracoglu, M. Soylak, D.S.K. Peker, L. Elci, W.N.L. dos Santos, V.A. Lemos and S.L.C. Ferreira, Anal. Chim. Acta 575, 133 (2006).

5. J.H. Wang and E.H. Hansen, J. Anal. At. Spectrom. 17, 1284 (2002).

6. Y.K. Wang, S.T. Gao, X.H. Zang, J.C. Li and J.J. Ma, Anal. Chim. Acta 716, 112 (2012).

7. H.M. Jiang, Z.P. Yan, Y. Zhao, X. Hu and H.Z. Lian, Talanta 94, 251 (2012).

8. F. Shah, T.G. Kazi, H.I. Afridi, Naeemullah, M.B. Arain and J.A. Baig, J. Hazard. Mater. 192, 1132 (2011).

9. C.Y. Zhang, Y.N. Wang, X.R. Cheng, Spectrosc. 32, 189 (2011).

10. P. Liang, R. Liu and J. Cao, Microchim. Acta 160, 135 (2008).

11. P. Liang, J. Yu, E.J. Yang and L.L. Peng, At. Spectrosc. 35, 85 (2014).

12. A.V. Herrera-Herrera, M. AsensioRamos, J. Hernandez-Borges and M.A. Rodriguez-Delgado, Trends Anal. Chem. 29, 728 (2010).

13. M. Rezaee, Y. Yamini and M. Faraji, J. Chromatogr. A 1217, 2342 (2010).

14. A.N. Anthemidis and K.I.G. Ioannou, Talanta 80, 413 (2009).

15. A. Zgola-Grzeskowiak and T. Grzeskowiak, Trends Anal. Chem. 30, 1382 (2011). H.B. Xia and P. Liang, At.

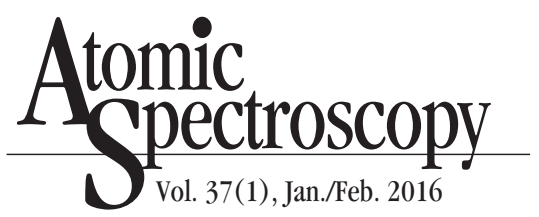

16. P. Wu, C.Y. Xu and X.D. Hou, Appl. Spectrosc. Rev. 48, 579 (2013).

17. X.P. Yan, Y. Li and Y. Jiang, J. Anal. At. Spectrom. 17, 610 (2002).

18. Y. Li, Y. Jiang, X.P. Yan and Z.M. Ni, Environ. Sci. Technol. 36, 4886 (2002).

19. L.M. Dong, X.P. Yan, Y. Li, Y. Jiang, S.W. Wang and D.Q. Jiang, J. Chromatogr. A 1036, 119 (2004).

20. X.P. Yan, Y. Li and Y. Jiang, Anal. Chem. 75, 2251 (2003).

21. J. Fang, Y. Jiang, X.P. Yan and Z.M. Ni, Environ. Sci. Technol. 39, 288 (2005).

22. C.K. Christou and A.N. Anthemidis, Talanta 78, 144 (2009).

23. P. Wu, Y. Gao, G.L. Cheng, W.S. Yang, Y. Lv and X.D. Hou, J. Anal. At. Spectrom. 23, 752 (2008).

24. Y. Gao, P. Wu, W. Li, Y.L. Xuan and X.D. Hou, Talanta 81, 586 (2010).

25. P. Liang, L.L. Zhang and E.H. Zhao, Talanta 82, 993 (2010).

26. S.Z. Mohammadi, Y.M. Baghelani and F. Mansori, Quim. Nova 35, 198 (2012).

27. P. Liang and H.B. Sang, Anal. Biochem. 380, 21 (2008). 